\title{
INVESTIGATING VOLATILITY BEHAVIOUR: EMPIRICAL EVIDENCE FROM ISLAMIC STOCK INDICES
}

\author{
Burhanuddin \\ Universitas Mulawarman, Indonesia, burhanuddin@feb.unmul.ac.id
}

\begin{abstract}
The main purpose of this research is to apply five univariate GARCH models to the daily stock returns of four major sharia stock indices. Two symmetric versions of the GARCH model (GARCH and MGARCH) and three asymmetric versions (EGARCH, TGARCH and PGARCH) are employed to estimate and forecast the volatility of four major sharia indices. The results provide strong evidence that all models can depict the volatility behaviours in all four sharia index returns. The two symmetric models indicate that the volatility of a sharia index's returns depend on its previous own lags, and statistically prove that a rise in volatility (risk) leads to an increase in mean (return), i.e. the risk premium effect. Meanwhile, the three asymmetric models suggest that negative shocks to daily returns tend to have higher impact on the volatility of sharia indices than positive shocks of the same magnitude. Moreover, based on the values of forecasting errors - root mean square errors (RMSE) and mean absolute errors (MAE) - the asymmetric GARCH models outperform the symmetric models in forecasting the volatility of four major sharia indices. However, the very small difference values of RMSE and MAE among the univariate GARCH-type models denote that no single model is superior to the others.
\end{abstract}

Keywords: Volatility, Forecasting, Islamic stock indices

JEL classification: C13; C22; C51; C58.

Article history:

Received : October 21, 2019

Revised : : August 4, 2020

Accepted : August 28, 2020

Available online : November 25, 2020

https://doi.org/10.21098/jimf.v6i4.1256 


\section{INTRODUCTION}

\subsection{Background}

Modelling and forecasting the time-series volatility of stock markets has arguably been one of the most intriguing topics within the field of empirical finance over recent decades. Many researchers have introduced different models under different assumptions, all aimed at investigating the behaviour of volatility and predicting future uncertainty. Moreover, volatility modelling provides a simple risk-management approach to calculating the value at risk of a financial position (Tsay, 2010) and is a key to finding the optimum portfolio allocation under the risk-return relationship. Hence, estimating the conditional variance of return series will enhance the efficiency of the estimated parameters, resulting in more precise forecasting of future uncertainty.

However, recent studies have only investigated the volatility of conventional stock-market indices. To address this gap in research, this study therefore investigates the unique topic of the Islamic financial markets. Interest in this aspect has increased because of the negative impacts of the recent global financial crisis on conventional financial markets. The topic of sharia stock volatility attracts attention for a number of reasons and from a variety of stakeholders, including governments as policy makers and investors and fund managers as practitioners.

Volatility is a measurement essential for understanding the risks of investing in Islamic financial assets. It is believed that sharia-based stocks have certain advantages compared to conventional assets that provide opportunities to diminish investment risks, boost returns, foster financial stability and gain the confidence of investors in the financial markets (Ben Nasr, Ajmi, \& Gupta, 2014). Given these factors, financial market participants are in search of more comprehensive studies that specifically investigate Islamic stock returns. Hence, the observing of the risk of stock-market volatility is an intriguing field particularly for those investors who are not only looking for returns but also wish to consider the principles of their religion (Chiadmi \& Ghaiti, 2014).

Despite the increase in issuance of Islamic financial assets over the past few years, empirical research on this subject is relatively scarce. There are only a few studies modelling volatility of sharia stock-market indices, including Yusof and Majid (2007), Abdalla and Winker (2012), Chiadmi and Ghaiti (2014) and Sclip, Dreassi, Miani, and Paltrinieri (2016). This paper therefore provides empirical evidence of volatility modelling and prediction for sharia equity indices by comparing evaluations of the volatility-predicting ability of symmetric and asymmetric generalised autoregressive conditional heteroscedasticity (GARCH)type models.

This research contributes to and improves upon previous studies in several ways. First, it does not, as in previous studies, only model volatility of a single stock market or local index within one country. Instead, we test four global Islamic indices. Second, by referencing UK and US equity indices, this research provides information about the volatility behaviour of Islamic equity indices produced in non-majority Muslim countries. 


\subsection{Objective}

The main purpose of this research is to apply five univariate GARCH-family models to the daily stock returns of four major Islamic (sharia) stock indices. GARCHtype models are employed to identify the behaviour of volatility, including volatility clustering and leverage effects. Having described the estimation results, we compare the forecasting results of the models. We use root mean square error (RMSE) and mean absolute error (MAE) to identify the most accurate models for use in forecasting the volatility of the four sharia indices.

The estimation results of five GARCH-type models show strong findings of stylised features such as volatility clustering, as well as the presence of asymmetric effects in the four sharia index returns. This evidence is confirmed by the results of forecasting performance showing that asymmetric GARCH-type models including EGARCH, TGARCH and PGARCH produce smaller forecasting errors (RMSE and MAE) than symmetric models. However, the very small difference values of RMSE and MAE among the univariate GARCH-type models indicate that no single model is superior to another in forecasting the returns of the four indices.

The structure of this paper is organised as follows: Section II provides the literature review, Section III explains the five univariate GARCH models employed in this paper, the descriptive statistics gathered and the preliminary tests used. Section IV discusses the empirical results for volatility using GARCH-class models and compares the result of out-of-sample forecasting. Finally, Section V presents conclusions and recommendations.

\section{LITERATURE REVIEW}

\subsection{Background theory}

One of the most intriguing topics in modern financial research is price changes in relation to stock-market volatility. Yan and Jiang (2008) explained various motives for research into stock-market behaviour and risk. First, the past price of volatility in short-term securities causes difficulties for investors in considering the changes caused by fundamental aspects of the economy. This will decrease their interest in investing and lead them to turn to other markets. Second, investors are mainly focused on the companies in which they invest, specifically the possibility of company default; normally, the higher the fluctuation of a company's value, the higher the probability of the company going into default. Third, volatility is a significant determining factor for the risk premium of financial assets: generally the larger the volatility, the larger the risk premium, with prices of assets usually having positive correlation with their volatility. Lastly, the assumptions of economics and finance are that most investors are normally risk averse, and so when the volatility of an investment project rises, the involvement of its investors will be decreased. For these particular reasons, and following the impact of the 1987 US stock-market crash, academicians started to devise methods for quantifying the risks of financial assets. 


\subsection{Previous studies}

Since the publication of a seminal paper by Engle (1982) introducing the first model for use in the study of volatility, this area of research has drawn immense attention from both researchers and practitioners. They believe that volatility is an important object for modelling and forecasting. Many researchers have used GARCH-type models to investigate the characteristics of volatility in financial markets. From these studies, it can be concluded that no single model is consistently superior to other models. Gokcan (2000) analysed the volatility of seven emerging stock markets by employing linear and non-linear versions of GARCH models and found that the EGARCH model was outperformed by the GARCH $(1,1)$ model. Poon and Granger (2003) surveyed 93 papers to evaluate the forecasting accuracy of all autoregressive conditional heteroscedasticity $(\mathrm{ARCH})$-type models and discovered that GARCH significantly outperformed ARCH. They also reported that asymmetric GARCH models such as TGARCH and EGARCH exhibited better performance than standard GARCH. Martens, De Pooter, and van Dijk (2004) compared the linear GARCH $(1,1)$ model and nonlinear EGARCH model for seven emerging countries and found that GARCH $(1,1)$ performed more accurate forecasting than the EGARCH model. Hansen and Lunde (2005) tested the ability of 330 different ARCH-family models to explain the volatility of exchange rates and stock returns. They discovered that GARCH $(1,1)$ had the best forecasting performance in comparison to other GARCH models. By using univariate GARCH-type models, Abdalla and Winker (2012) found that the conditional variance of Sudan's and Egypt's stock markets was positively correlated to expected returns. Hence, there is also strong evidence of a leverage effect or an asymmetric response in the return series of both markets. Wennstrom (2014) forecast Nordic stock indices using GARCH models and concluded that no model could be highly recommended by looking at all loss functions in out-ofsample forecasting performance.

Furthermore, there are some related findings that provide significant evidence in studying financial time series under the influence of structural changes in volatility (Andreou \& Ghysels, 2002; Rapach \& Strauss, 2008; Rapach, Strauss, \& Wohar, 2008). Thus, this paper considers investigating the significance of structural breaks by allowing the volatility of returns to have such characteristics. Specifically, our interest in studying the volatility of Islamic indices is in response to previous studies of this topic. Employing MGARCH and GARCH $(1,1)$ models to investigate the volatility of the Islamic and conventional equity markets in Malaysia, Yusof and Abdul Majid $(2006 ; 2007)$ reported that conditional standard deviation had no impact on equity returns during the observation period. A paper by Chiadmi and Ghaiti (2012) applied the GARCH model to analysis of the persistence of the Islamic sharia S\&P 500 index and the S\&P conventional index. The results showed that the volatility of these indices was significant and that the conventional S\&P 500 index was more volatile than the Islamic sharia S\&P 500. In terms of structural changes, recent research by Ben Nasr et al. (2014) suggested that structural changes be accounted for in modelling the conditional variance of the Dow Jones Islamic World Index (DJIM), one of the Islamic indices studied in this paper. 


\section{METHODOLOGY}

\subsection{Data}

The time-series data observed in this research are the daily closing prices of four major sharia equity indices: the FTSE All-World Shariah Index (FTSE: SWORLDS), the Dow Jones Islamic Market World Index (DJIM), the MSCI World Islamic Index (MSCI: MIWO), and the S\&P Global BMI Shariah Index (S\&P: SPSHGLUP). All four indices are entirely composed of sharia-compliant stocks. These prices were collected from Bloomberg Professional Services over the period of 1 January 2007 to 31 December 2016, resulting in a total of 2368 observations for S\&P, 2437 observations for MSCI, 2866 observations for DJIM, and 2605 observations for FTSE.

Daily returns $(r)_{t}$ were computed as the continuously compounded returns using logarithms of the four indices $(p)$, as follows:

$$
r_{t}=\log \frac{p_{t}}{p_{t-1}}
$$

where $p_{t}$ is the value of the equity index at day $t$ and $p_{t-1}$ is the value of the equity index at the previous day $(t-1)$.

\subsection{Model Development}

The maximum-likelihood (ML) method was employed to estimate different GARCH models under the assumption of Gaussian distribution (Xie, 2007). The aim of this method is to find the most plausible parameter values for the observed data. Specifically, a log-likelihood function was formed to find the optimal function of the values of the parameters. The ML estimation was applied for both symmetric and asymmetric GARCH models to find their coefficient values. Having identified the occurrence of structural changes and found the breakpoint test explained in the previous section, this research considers a dummy variable, namely CRISIS, added into the mean equation. The dummy was set at 1 from the structural break date until the end of the period and at 0 from the beginning of the period until one day before the structural break. Therefore, the specification of the mean equation is as follows:

$$
\text { Mean equation: } r=\mu+C R I S I S+\varepsilon
$$

\subsection{Method}

The methodologies employed in this research are the GARCH model and its extensions. This model is commonly used in empirical finance to model and forecast volatility in financial markets. GARCH-type models are widely used in practice because they can solve some of the main problems experienced in ARCH models, such as the leverage effect and the violation of non-negativity constraints.

In this paper, we employ five different univariate GARCH-type models in estimating the volatility of the stock returns of four major sharia indices. 
Specifically, GARCH-type models are divided into two categories, to which the GARCH and GARCH-M models are applied for investigating symmetric effects in the estimated volatility model, whilst the TGARCH and EGARCH models are applied for investigating asymmetric effects in conditional variance.

All five different GARCH models focus on the lowest order $(1,1)$ or the simplest specification, because this approach can most easily show the strengths and weaknesses of GARCH models (Tsay, 2010). Further discussion of each model will then be presented, in which each model has a different specification for solving a different problem of modelling volatility. There are two equations provided for each model, the first for the conditional mean and the second for conditional variance. However, the focus of this study is on conditional variance, as this specifies the estimation and conditional forecasting of volatility.

\subsubsection{Generalised Autoregressive Conditional Heteroscedasticity (GARCH) Model}

The GARCH model was introduced by Bollerslev (1986), and is an extension of the ARCH model with the addition of its own lagged conditional variance term during the previous period into current conditional variance. Hence, this model is considerably more parsimonious and avoids overfitting.

$$
\sigma_{t}^{2}=\alpha_{0^{+}} \sum_{i=1}^{q} \alpha_{i} \varepsilon_{t-i}^{2}+\sum_{j=1}^{p} \beta_{j} \sigma_{t-j}^{2}
$$

where $q=\operatorname{lag}(\mathrm{s})$ of the squared residualand $p=\operatorname{lag}(\mathrm{s})$ of the conditional variance

This research applies the GARCH $(1,1)$ model because it provides the simplest equation showing the benefits and drawbacks of GARCH models. The GARCH $(1,1)$ model can be specified by the following equations:

Mean equation: $\quad r_{t}=\mu+\varepsilon_{t}$

Variance equation: $\sigma_{t}^{2}=\alpha_{0}+\alpha_{1} \varepsilon_{t-1}^{2}+\beta_{1} \sigma_{t-1}^{2}$

where $\alpha_{1} \geq 0, \beta_{1} \geq 1$, and $\sum_{i=1}^{\max (p, q)}\left(\alpha_{1}+\beta_{1}\right)<1$ :

$r_{t}=$ stock returns at time $\mathrm{t}$

$\mu=$ average returns (constant)

$\varepsilon_{t}=$ residual returns, defined by the following equation:

$\varepsilon_{t}=\sigma_{t} \epsilon_{t}$

where $\epsilon_{t}$ is a sequence of independently and identically distributed (IID) random variables with mean of 0 and variance of 1 , where $\sigma_{t}^{2}$ represents the conditional variance; $\alpha_{1} \geq 0$ and $\beta_{1} \geq 1$ are non-negativity constraints; and $\left(\alpha_{1}+\beta_{1}\right)<1$ means that the unconditional variance of $\varepsilon_{t}$ is limited to no more than 1 (Tsay, 2010). 
This model focuses on estimated conditional variance to reveal the behaviour of conditional heteroscedasticity. The value of conditional variance $\sigma_{t}^{2}$ is determined by two parameters. First, it depends on the previous values of the squared residual in which $\alpha_{1}$ is a coefficient of the squared lag of residual term $\varepsilon_{t-1}^{2}$. Second, it is determined by its own previous lagged values $\sigma_{t-1}^{2}$ with $\beta_{1}$ as a coefficient. Consequently, GARCH $(1,1)$ provides an opportunity to capture conditional variance behaviour as a large or small increase in $\varepsilon_{t-1}^{2}$ or $\sigma_{t-1}^{2}$ resulting in a large or small increase in $\sigma_{t}^{2}$, known as volatility clustering. Thus, compared to the ARCH model, the GARCH $(1,1)$ model is considered a better model.

\subsubsection{Generalised Autoregressive Conditional Heteroscedasticity in Mean (GARCH-M) Model}

Engle et al. (1987) were the first to develop the ARCH-M model, stating that the conditional mean (return) depends on its conditional variance (volatility). However, since the GARCH model is preferred to ARCH model, it is better to estimate using the generalised version of the ARCH-M model (Brooks, 2014). Another variant of the GARCH-M-type model captures risk not through variance but by using the standard deviation of the series (Asteriou \& Hall, 2011). Moreover, this model operates under the assumption that investors always require extra return for taking any additional risk when buying a risky asset, known as risk premium theory. If conditional variance or volatility captures risk, then the parameter of the risk premium will be added as a coefficient of the conditional variance. Thus, the simple equation of the GARCH-M $(1,1)$ model can be written by the following equations:

$$
\begin{aligned}
& \text { Mean equation: } r_{t}=\mu+\lambda \sigma_{t}^{2}+\varepsilon_{t} \\
& \text { Variance equation: } \sigma_{t}^{2}=\alpha_{0}+\alpha_{1} \varepsilon_{t-1}^{2}+\beta_{1} \sigma_{t-1}^{2}
\end{aligned}
$$

where $\lambda=$ risk premium coefficient

A positive value of $\lambda$ means that the return has a positive linear correlation with its conditional variance. In other words, an increase in volatility will increase the mean return, as a proxy for taking more risk. Hence, the specified equation of MGARCH also indicates that there is autocorrelation in the series of return $r_{t}$.

\subsubsection{Exponential Generalised Autoregressive Conditional Heteroscedasticity (EGARCH) Model}

The EGARCH model was firstly proposed by Nelson (1991) and can be specified by the following equation:

$$
\ln \left(\sigma_{t}^{2}\right)=\alpha_{0}+\sum_{i=1}^{q} \alpha_{i}\left[\frac{\left|\varepsilon_{t-i}\right|}{\sqrt{\sigma_{t-i}^{2}}}-\sqrt{\frac{2}{\pi}}\right]+\frac{\theta_{i} \varepsilon_{t-i}}{\sqrt{\sigma_{t-i}^{2}}}+\sum_{j=1}^{p} \beta_{j} \ln \left(\sigma_{t-j}^{2}\right)
$$


where $q=\operatorname{lag}(\mathrm{s})$ of the squared residualand $p=\operatorname{lag}(\mathrm{s})$ of conditional variance

This research applies the EGARCH $(1,1)$ model, as it provides the simplest equation. The EGARCH $(1,1)$ model is specified as follows:

$$
\ln \left(\sigma_{t}^{2}\right)=\alpha_{0}+\alpha_{1}\left[\frac{\left|\varepsilon_{t-1}\right|}{\sqrt{\sigma_{t-1}^{2}}}-\sqrt{\frac{2}{\pi}}\right]+\frac{\theta \varepsilon_{t-1}}{\sqrt{\sigma_{t-1}^{2}}}+\beta_{1} \ln \left(\sigma_{t-1}^{2}\right)
$$

It is noticeable that the variance equation uses a log or exponential for its conditional variance. This guarantees that even if the parameters are negative, the value of conditional variance $\sigma_{t}^{2}$ will always be positive. Therefore, the EGARCH model does not need to create additional non-negativity constraints on the parameters of the estimated model. Moreover, under the EGARCH model assumption, if volatility and returns are negatively correlated, the value of $\theta$ will be negative.

In this model, $\theta$ represents the asymmetrical response coefficient of the leverage parameter. Hence, if $\theta=0$ the model is symmetric. If $\theta<0$ the model is asymmetric, meaning that bad news will have a larger impact on future volatility or uncertainty than good news of the same magnitude. As this model captures asymmetric response, the value of $\theta$ is expected to be negative (Tsay, 2010).

\subsubsection{Threshold Generalised Autoregressive Conditional Heteroscedasticity (TGARCH) Model}

The first asymmetric GARCH models which offered to overcome the asymmetrical issue of volatility were the threshold GARCH (T-GARCH) model introduced by Zakoian (1994) and the GJR GARCH by Glosten, Jagannathan, and Runkle (1993). Although these two models have different names they exactly estimate similar specifications and so will be referred to in this study as TGARCH. The aim of the TGARCH model is to capture the asymmetrical effect of positive and negative shocks using a parameter $\theta$ and multiplying it by a dummy variable $\left(d_{t-1}\right)$. Then, this additional equation is added into the estimated conditional variance to measure the significance level of the differential impact of negative shocks. Therefore, the variance equation of TGARCH is specified as follows:

$$
\sigma_{t}^{2}=\alpha_{0}+\sum_{i=1}^{q}\left(\alpha_{i}+\theta_{i} d_{t-i}\right) \varepsilon_{t-i}^{2} \sum_{j=1}^{p} \beta_{j} \sigma_{t-j}^{2}
$$

where $q=\operatorname{lag}(\mathrm{s})$ of the squared residual and $p=\operatorname{lag}(\mathrm{s})$ of the conditional variance

This research applies the TGARCH $(1,1)$ model, as it provides the simplest equation, specified as follows:

$$
\sigma_{t}^{2}=\alpha_{0}+\alpha_{1} \varepsilon_{t-1}^{2}+\theta \varepsilon_{t-1}^{2} d_{t-1}+\beta_{1} \sigma_{t-1}^{2}
$$


where $d_{t-1}$ is an indicator for negative shocks $\varepsilon_{t-1}$ : that is;

$\begin{aligned} d_{t-1} & =1 \text { if } \varepsilon_{t-1}<0 \\ & =0 \text { if } \varepsilon_{t-1} \geq 0\end{aligned}$

and $\alpha_{1}, \theta$, and $\beta_{1}$ are positive parameters implying similar condition to those of standard GARCH models.

This model is therefore called threshold GARCH because it uses zero as its threshold to separate the effects of past shocks (Tsay, 2010). Specifically, if $\varepsilon_{t-1}=0$ is used as a threshold, shocks larger than zero will have a different impact to shocks below zero. If $\theta>0$, this indicates that the leverage effect exists, such that a negative value of $\varepsilon_{t-1}$ (negative shock) has a larger impact $\left(\alpha_{1}+\theta\right) \varepsilon_{t-1}^{2}$ on the value of $\sigma_{t}^{2}$, whereas if $\varepsilon_{t-1}$ is positive (positive shock) and $\theta=0$ it only contributes $\alpha_{1} \varepsilon_{t-1}^{2}$, indicating there is no presence of a leverage effect. In other words, the existence of a leverage effect means that there is an asymmetrical response, whilst symmetry means that the leverage effect does not exist during the observation period.

\subsubsection{Power Generalised Autoregressive Conditional Heteroscedasticity (PGARCH) Model}

The PGARCH model was proposed by Ding, Granger, and Engle (1993), and unlike other asymmetric models it allows researchers to model conditional standard deviation instead of conditional variance. By investigating the 'long memory' feature of the stock-market return series, the researchers found that outside the Gaussian framework the superiority of the squared (Bollerslev's GARCH model) or absolute (Taylor's GARCH model) term was lost.

Moreover, this model is also based on findings by Granger Spear, and Ding (2000), who discovered empirical evidence that the presence of a serial correlation is stronger in absolute returns than in squared returns (Penzer, Wang, \& Yao, 2009). PGARCH also states that the power term $\delta$ is endogenised to consider the possibility that other power transformations may be optimal, specifically when excess kurtosis and skewness exist in the data set (Ané, 2006). Consequently, the PGARCH model uses $\sigma_{t}^{\delta}$ instead of squared $\sigma_{t}^{2}$ in the equation of conditional standard deviation. The complete equation can be formulated as follows:

$$
\sigma_{t}^{\delta}=\alpha_{0}+\sum_{i=1}^{p} \alpha_{i}\left(\left|\varepsilon_{t-i}\right|-\theta_{i} \varepsilon_{t-1}\right)^{\delta}+\sum_{j=1}^{q} \beta_{i} \sigma_{t-i}^{\delta}
$$

where $q=\operatorname{lag}(\mathrm{s})$ of the residual and $p=\operatorname{lag}(\mathrm{s})$ of the conditional variance, and $\delta \geq 0$

This research applies the PGARCH $(1,1)$ model, as it provides the simplest equation, specified as follows:

$$
\sigma_{t}^{\delta}=\alpha_{0}+\alpha_{1}\left(\left|\varepsilon_{t-1}\right|-\theta_{1} \varepsilon_{t-1}\right)^{\delta}+\beta_{1} \sigma_{t-1}^{\delta}
$$


where $\alpha_{1}$ is the standard parameter of $\mathrm{ARCH}$ and $\beta_{1}$ is the standard parameter of GARCH. The parameter $\theta$ represents an asymmetric effect of previous shocks and $\delta$ represents the parameter of the optimal power transformation. If $\delta=1$, the standard equation becomes Taylor's GARCH whilst if $\delta=2$, it becomes the standard GARCH by Bollerslev.

\section{RESULTS AND ANALYSIS}

\subsection{Results}

A table is provided for each Islamic index. These tables show the estimation outputs of various GARCH-family models. Additionally, diagnostics testing is also performed to identify the existence of $\mathrm{ARCH}$ effects in the residuals of each model. The estimation outputs for each of five different GARCH models are provided below for S\&P, MSCI, DJIM and FTSE, respectively.

Table 1.

Estimation Results of GARCH-Family Models for the S\&P Global BMI Shariah Index

\begin{tabular}{|c|c|c|c|c|c|}
\hline Coefficients & $\begin{array}{c}\text { GARCH } \\
(1,1)\end{array}$ & $\begin{array}{c}\text { GARCH-M } \\
(1,1)\end{array}$ & $\begin{array}{c}\text { EGARCH } \\
(1,1)\end{array}$ & $\begin{array}{c}\text { TGARCH } \\
(\mathbf{1}, \mathbf{1})\end{array}$ & $\begin{array}{c}\text { PGARCH } \\
(1,1)\end{array}$ \\
\hline \multicolumn{6}{|c|}{ Mean equation } \\
\hline$\mu$ & -0.00077 & - & - & - & -0.000687 \\
\hline CRISIS & $0.001216^{* *}$ & $0.001788^{*}$ & 0.00068 & 0.000587 & 0.00067 \\
\hline$\lambda$ & - & $0.202779 *$ & - & - & - \\
\hline \multicolumn{6}{|c|}{ Variance equation } \\
\hline$\alpha_{0}$ & $1.65 \mathrm{E}-06^{*}$ & $1.61 \mathrm{E}-06^{*}$ & $-0.268224^{*}$ & $1.72 \mathrm{E}-06^{*}$ & $0.000306^{* * *}$ \\
\hline$\alpha_{1}$ & $0.110224^{*}$ & $0.10926^{*}$ & $0.129926^{*}$ & 2.19E-05 & $0.079871^{*}$ \\
\hline$\beta_{1}$ & $0.874729^{*}$ & $0.876004^{*}$ & $0.982177^{*}$ & $0.894438^{*}$ & $0.969312^{*}$ \\
\hline$\theta$ & - & - & $-0.12991^{*}$ & $0.172508^{*}$ & $0.924924^{*}$ \\
\hline$\delta$ & - & - & - & - & $0.891067^{*}$ \\
\hline$\alpha_{1}+\beta_{1}$ & 0.984953 & 0.985264 & $1.6 \mathrm{E}-05$ & 0.1725299 & 1.049183 \\
\hline log likelihood & 7913.256 & 7918.166 & 7967.996 & 7953.828 & 7974.809 \\
\hline \multicolumn{6}{|c|}{ ARCH-LM test for heteroscedasticity } \\
\hline Statistic & 8.714407 & 7.953961 & 5.94401 & 7.084278 & 5.646101 \\
\hline Prob. & 0.121 & 0.1588 & 0.3117 & 0.2144 & 0.3422 \\
\hline
\end{tabular}

Notes: ${ }^{*}=$ significant at $1 \%$ level, ${ }^{* *}=$ significant at $5 \%$ level, ${ }^{* * *}=$ significant at $10 \%$ level

The variance equation output of $\operatorname{GARCH}(1,1)$ displayed in Table 1 shows that the three parameters of intercept $\left(\alpha_{0}\right)$, ARCH term $\left(\alpha_{1}\right)$, and GARCH term $\left(\beta_{1}\right)$ are statistically significant at the $1 \%$ level. This is a sign of the existence of $\mathrm{ARCH}$ and GARCH processes in S\&P and also implies that the parameter values of the lagged squared residual and lagged conditional variance affect the value of conditional variance. The GARCH-M $(1,1)$ model allows the conditional mean equation (return) to be dependent on a function of the conditional variance $(\lambda)$, the estimation output reported in Table 1 shows a positive value of $\lambda$, and it is statistically significant at the $1 \%$ and $5 \%$ levels. 
The estimation outputs of the EGARCH $(1,1)$ model indicate that all the estimated coefficients are significantly different from 0 at the $1 \%$ confidence level. The leverage effect also exists in the S\&P index, as shown by the negative values of $\theta$ which are statistically significant. Another version for testing an asymmetric effect but with non-negativity constraints is the TGARCH $(1,1)$ model. As reported in Table 1, the coefficients $\theta$ of the leverage effect parameter of S\&P have positive values and are statistically significant at the $1 \%$ confidence level. The asymmetric GARCH-family model tested in this research is the PGARCH. As shown in the estimation outputs of PGARCH, the estimated parameters $\theta$ of S\&P are statistically different from 0 at the $1 \%$ level and have positive values.

Table 2.

Estimation Results of GARCH-Family Models for the MSCI World Islamic Index

\begin{tabular}{|c|c|c|c|c|c|}
\hline Coefficients & GARCH $(1,1)$ & $\begin{array}{c}\text { GARCH-M } \\
(1,1)\end{array}$ & $\begin{array}{c}\text { EGARCH } \\
(1,1)\end{array}$ & $\begin{array}{c}\text { TGARCH } \\
(1,1)\end{array}$ & PGARCH $(1,1)$ \\
\hline \multicolumn{6}{|c|}{ Mean equation } \\
\hline $\bar{\mu}$ & -0.000535 & - & - & - & -0.000356 \\
\hline CRISIS & $0.00092^{* * *}$ & $0.001312^{*}$ & 0.000331 & 0.00032 & 0.000322 \\
\hline$\lambda$ & - & $0.169058^{*}$ & - & - & - \\
\hline \multicolumn{6}{|c|}{ Variance equation } \\
\hline$\alpha_{0}$ & $0.00000158^{*}$ & $0.00000156^{*}$ & $-0.255956^{*}$ & 1.74E-06* & $0.000497^{* * *}$ \\
\hline$\alpha_{1}$ & $0.104783^{*}$ & $0.104336^{*}$ & $0.131035^{*}$ & 0.0105 & $0.078117^{*}$ \\
\hline$\beta_{1}$ & $0.882389^{*}$ & $0.882891^{*}$ & $0.983502^{*}$ & $0.89628^{*}$ & $0.871232^{*}$ \\
\hline$\theta$ & - & - & $-0.113623^{*}$ & $0.150237^{*}$ & $0.928607^{*}$ \\
\hline$\delta$ & - & - & - & - & $0.769993^{*}$ \\
\hline$\alpha_{1}+\beta_{1}$ & 0.987172 & 0.987227 & 0.017412 & 0.160737 & 0.949349 \\
\hline log likelihood & 8027.651 & 8031.207 & 8076.323 & 8060.415 & 8083.088 \\
\hline \multicolumn{6}{|c|}{ ARCH-LM test for heteroscedasticity } \\
\hline $\begin{array}{l}\text { Statistic } \\
\text { nat }\end{array}$ & 11.10191 & 10.1558 & 6.198799 & 7.928193 & 5.642847 \\
\hline Prob. & 0.0494 & 0.0709 & 0.2874 & 0.1602 & 0.3425 \\
\hline
\end{tabular}

Notes: ${ }^{*}=$ significant at $1 \%$ level, ${ }^{* *}=$ significant at $5 \%$ level, ${ }^{* * *}=$ significant at $10 \%$ level

The variance equation output of GARCH $(1,1)$ displayed in Table 2 shows that the three parameters of intercept $\left(\alpha_{0}\right)$, ARCH term $\left(\alpha_{1}\right)$, and GARCH term $\left(\beta_{1}\right)$ are statistically significant at the $1 \%$ level. This is a sign of the existence of $\mathrm{ARCH}$ and GARCH processes in MSCI. It also implies that the parameter values of the lagged squared residual and lagged conditional variance affect the value of conditional variance. The GARCH-M $(1,1)$ model allows the conditional mean equation (return) to be dependent on a function of the conditional variance $(\lambda)$, the estimation output reported in Table 2 shows a positive value of $\lambda$, and is statistically significant at the $1 \%$ and $5 \%$ levels.

The estimation outputs of the EGARCH $(1,1)$ model show that all the estimated coefficients are significantly different from 0 at the $1 \%$ confidence level. The leverage effect also exists in MSCI index, as shown by the negative values of $\theta$ which are statistically significant. Another version for testing an asymmetric effect but with non-negativity constraints is the TGARCH $(1,1)$ model. As reported in Table 1, the 
coefficients $\theta$ of the leverage effect parameter of MSCI have positive values and are statistically significant at the $1 \%$ confidence level. The other asymmetric GARCHfamily model tested in this research is the PGARCH. As shown in the estimation outputs of PGARCH, the estimated parameters $\theta$ of MSCI are statistically different from 0 at the $1 \%$ level and have positive values.

Table 3.

Estimation Results of GARCH-Family Models for the DJIM World Index

\begin{tabular}{|c|c|c|c|c|c|}
\hline Coefficients & $\begin{array}{c}\text { GARCH } \\
(1,1)\end{array}$ & $\begin{array}{c}\text { GARCH-M } \\
(1,1)\end{array}$ & $\begin{array}{c}\text { EGARCH } \\
(1,1)\end{array}$ & $\begin{array}{c}\text { TGARCH } \\
(1,1)\end{array}$ & $\begin{array}{c}\text { PGARCH } \\
(1,1)\end{array}$ \\
\hline \multicolumn{6}{|c|}{ Mean equation } \\
\hline $\bar{\mu}$ & 5.30E-05 & - & - & - & $0.000359^{* *}$ \\
\hline CRISIS & 0.000321 & $0.000516^{* * *}$ & $-0.000497^{*}$ & -0.000101 & $-0.000409^{*}$ \\
\hline$\lambda$ & - & $0.149785^{*}$ & - & - & - \\
\hline \multicolumn{6}{|c|}{ Variance equation } \\
\hline$\overline{\alpha_{0}}$ & $1.38 \mathrm{E}-06^{*}$ & $1.34 \mathrm{E}-06^{*}$ & $-0.254292^{*}$ & $1.50 \mathrm{E}-06^{*}$ & $0.000402^{* *}$ \\
\hline$\alpha_{1}$ & $0.099468^{*}$ & $0.099354^{*}$ & $0.110726^{*}$ & $2.70 \mathrm{E}-03$ & $0.071322^{*}$ \\
\hline$\beta_{1}$ & $0.885765^{*}$ & $0.886554^{*}$ & $0.982086^{*}$ & $0.900704^{*}$ & $0.961893^{*}$ \\
\hline$\theta$ & - & - & $-0.116851^{*}$ & $0.152463^{*}$ & $0.932776^{*}$ \\
\hline$\delta$ & - & - & - & - & $0.828246^{*}$ \\
\hline$\alpha_{1}+\beta_{1}$ & 0.985233 & 0.985908 & -0.006125 & 0.155162 & 1.033215 \\
\hline log likelihood & 9756.926 & 9760.531 & 9817.778 & 9800.545 & 9827.002 \\
\hline \multicolumn{6}{|c|}{ ARCH-LM test for heteroscedasticity } \\
\hline Statistic & 8.492631 & 8.294078 & 5.567262 & 7.111912 & 5.591951 \\
\hline Prob. & 0.1311 & 0.1408 & 0.3506 & 0.2124 & 0.348 \\
\hline
\end{tabular}

The variance equation output of GARCH $(1,1)$ displayed in Table 3 shows that the three parameters of intercept $\left(\alpha_{0}\right)$, ARCH term $\left(\alpha_{1}\right)$, and GARCH term $\left(\beta_{1}\right)$ are statistically significant at the $1 \%$ level. This is a sign of the existence of $\mathrm{ARCH}$ and GARCH process in DJIM. It also implies that the parameter values of the lagged squared residual and lagged conditional variance affect the value of conditional variance. The GARCH-M $(1,1)$ model allows the conditional mean equation (return) to be dependent on a function of the conditional variance $(\lambda)$, the estimation output reported in Table 3 shows a positive value of $\lambda$, and it is statistically significant at the $1 \%$ and $5 \%$ levels.

The estimation outputs of the EGARCH $(1,1)$ model show that all the estimated coefficients are significantly different from 0 at the $1 \%$ confidence level. The leverage effect also exists in the DJIM index as shown by the negative values of $\theta$ which are statistically significant. Another version for testing an asymmetric effect but with non-negativity constraints is the TGARCH $(1,1)$ model. As reported in Table 1, the coefficients $\theta$ of the leverage effect parameter of DJIM have positive values and are statistically significant at the $1 \%$ confidence level. The other model of asymmetric GARCH-family models tested in this research is the PGARCH. As shown in the estimation outputs of PGARCH, the estimated parameters $\theta$ of DJIM are statistically different from 0 at the $1 \%$ level and have positive values. 
Table 4.

Estimation Result of GARCH-Family Models for the FTSE All-World Shariah Index

\begin{tabular}{|c|c|c|c|c|c|}
\hline Coefficients & $\begin{array}{c}\text { GARCH } \\
(1,1)\end{array}$ & $\begin{array}{c}\text { GARCH-M } \\
(1,1)\end{array}$ & $\begin{array}{c}\text { EGARCH } \\
(1,1)\end{array}$ & $\begin{array}{c}\text { TGARCH } \\
(1,1)\end{array}$ & $\begin{array}{c}\text { PGARCH } \\
(1,1)\end{array}$ \\
\hline \multicolumn{6}{|c|}{ Mean equation } \\
\hline$\mu$ & $1.68 \mathrm{E}-05$ & - & - & - & 3.94E-05 \\
\hline CRISIS & 0.000343 & 0.000543 & -0.000129 & 2.51E-05 & $-6.22 \mathrm{E}-05$ \\
\hline$\lambda$ & - & $0.15156^{* *}$ & - & - & - \\
\hline \multicolumn{6}{|c|}{ Variance equation } \\
\hline$\alpha_{0}$ & $1.45 \mathrm{E}-06^{*}$ & $1.43 \mathrm{E}-06^{*}$ & $-0.243921^{*}$ & $1.68 \mathrm{E}-06^{*}$ & $0.000578^{* *}$ \\
\hline$\alpha_{1}$ & $0.098988^{*}$ & $0.099015^{*}$ & $0.116592^{*}$ & 8.39E-03 & $0.07312^{*}$ \\
\hline$\beta_{1}$ & $0.887511^{*}$ & $0.887719^{*}$ & $0.983781^{*}$ & $0.899259^{*}$ & $0.932056^{*}$ \\
\hline$\theta$ & - & - & $-0.110428^{*}$ & $0.144696^{*}$ & $0.902039^{*}$ \\
\hline$\delta$ & - & - & - & - & $0.738072^{*}$ \\
\hline$\alpha_{1}+\beta_{1}$ & 0.986499 & 0.986734 & 0.006164 & 0.153088 & 0.975159 \\
\hline log likelihood & 8702.044 & 8705.128 & 8754.184 & 8736.962 & 8761.892 \\
\hline \multicolumn{6}{|c|}{ ARCH-LM test for heteroscedasticity } \\
\hline Statistic & 7.296394 & 6.600607 & 5.003466 & 6.709874 & 4.52013 \\
\hline Prob. & 0.1995 & 0.2521 & 0.4155 & 0.2431 & 0.4772 \\
\hline
\end{tabular}

The variance equation output of GARCH $(1,1)$ displayed in Table 4 shows that the three parameters of intercept $\left(\alpha_{0}\right)$, ARCH term $\left(\alpha_{1}\right)$, and GARCH term $\left(\beta_{1}\right)$ are statistically significant at the $1 \%$ level. This is a sign of the existence of $\mathrm{ARCH}$ and GARCH processes in FTSE. It also implies that the parameter values of the lagged squared residual and lagged conditional variance affect the value of conditional variance. The GARCH-M $(1,1)$ model allows the conditional mean equation (return) to be dependent on a function of the conditional variance $(\lambda)$, the estimation output reported in Table 4 shows a positive value of $\lambda$, and it is statistically significant at the $1 \%$ and $5 \%$ levels.

The estimation outputs of the EGARCH $(1,1)$ model show that all the estimated coefficients are significantly different from 0 at the $1 \%$ confidence level. The leverage effect also exists in the FTSE index, as shown by the negative values of $\theta$ which are statistically significant. Another version for testing an asymmetric effect but with non-negativity constraints is the TGARCH $(1,1)$ model. As reported in Table 1, the coefficients $\theta$ of the leverage effect parameter of the FTSE have positive values and are statistically significant at the $1 \%$ confidence level. The other model of asymmetric GARCH-family models tested in this research is the PGARCH. As shown in the estimation outputs of PGARCH the estimated parameters $\theta$ of FTSE are statistically different from 0 at the $1 \%$ level and have positive values.

The outputs of diagnostic tests for testing the ARCH effects are presented in the lower parts of Tables 1, 2, 3, and 4. The ARCH-LM test for heteroscedasticity of all GARCH models reports that there are no $\mathrm{ARCH}$ effects remaining in the error terms of the estimated models. This is confirmed by the probability values of all univariate GARCH-type models which are not statistically significant. This indicates that univariate GARCH-type models can effectively specify the conditional variance equations of the S\&P, MSCI, DJIM and FTSE sharia indices. 
Since the future values of the observed data are unknown, we then kept a part of the observation data back as a holdout sample. We obtained the holdout sample by creating a sub-sample from observed data for estimated GARCH models. The sub-sample ran from 1 January 2007 to 31 December 2014. In other words, we performed two-year out-of-sample forecasting from 1 January 2015 to 31 December 2016.

Table 5.

RMSE and MAE Values of Four Islamic Indices

\begin{tabular}{lccc}
\hline Sharia indices & GARCH Model & RMSE & MAE \\
\hline \multirow{4}{*}{ S\&P } & GARCH & 0.010869 & 0.007124 \\
& MGARCH & 0.0108894 & 0.007136 \\
& TGARCH & 0.010861 & 0.007129 \\
& EGARCH & 0.010861 & 0.007130 \\
PGARCH & 0.010861 & 0.007129 \\
\hline \multirow{4}{*}{ MSCI } & GARCH & 0.011253 & 0.007457 \\
& MGARCH & 0.011278 & 0.007471 \\
& TGARCH & 0.011248 & 0.007460 \\
& EGARCH & 0.011247 & 0.007461 \\
& PGARCH & 0.011247 & 0.007462 \\
\hline \multirow{4}{*}{ DJIM } & GARCH & 0.01036 & 0.006553 \\
& MGARCH & 0.010378 & 0.006583 \\
& TGARCH & 0.010355 & 0.006542 \\
& EGARCH & 0.010355 & 0.006540 \\
FTSE & PGARCH & 0.010354 & 0.006539 \\
\hline & GARCH & 0.010755 & 0.007166 \\
& MGARCH & 0.010775 & 0.007172 \\
& TGARCH & 0.010749 & 0.007172 \\
& EGARCH & 0.010749 & 0.007173 \\
\end{tabular}

The data presented in Table 5 shows that for the S\&P index, TGARCH and PGARCH have the smallest RMSE and MAE values, indicating that these two models are best for forecasting the volatility of the S\&P index compared to the other GARCH models. For the MSCI index, EGARCH has the smallest RMSE and MAE values, meaning that this model can forecast the volatility of MSCI better than the other GARCH models. For the DJIM index, PGARCH has the best forecasting performance, as shown by its RMSE and MAE values, which are the smallest among the GARCH models. This implies that PGARCH is the best-fitted model for forecasting the volatility of the DJIM. Finally, for the FTSE index, TGARCH and PGARCH have the same and the smallest values of RMSE and MAE, implying that these two models can forecast the volatility of the FTSE more accurately than the other GARCH models. Based on the values of these forecasting errors, we concluded that the asymmetric GARCH models outperformed the symmetric GARCH models. However, the very small difference values of RMSE and MAE among the univariate GARCH-type models indicate that no single univariate 
model is superior to other univariate models in forecasting the volatility of four major Islamic indices.

\subsection{Analysis}

Based on the empirical results above, this study finds significant evidence that univariate GARCH-type models can effectively specify the daily returns of four major Islamic indices. Either from the fitting effect or the level of estimation accuracy, GARCH-type models can appropriately capture one of the main characteristics of financial time series: volatility clustering in all four Islamic indices. In other words, previous shocks in volatility, either positive or negative, have an impact on the current volatility of Islamic stock price. Moreover, both the GARCH $(1,1)$ and MGARCH models (representing the symmetric models) and TGARCH $(1,1)$, EGARCH $(1,1)$, and PGARCH (representing the asymmetric models) present reliable estimations. Specifically, since the forecasting errors of the asymmetric GARCH models are lower than the symmetric GARCH models, we conclude that the asymmetric GARCH models capture more details than the symmetric ones. In addition, one notable TGARCH estimation result is that the ARCH term is not statistically significant. This indicates that TGARCH could not detect and statistically prove the presence of volatility clustering in Islamic indices as significantly as other univariate GARCH-type models.

Furthermore, the four Islamic indices reflect the overall situation of the market fluctuations of Islamic/sharia stock-market indices, and the S\&P, DJIM, MSCI and FTSE indices produced by the four main world stock markets can to a certain extent reflect the whole situation in Islamic/sharia stock markets. Therefore, the results we have identified in this research are also likely, to a certain extent, to be applicable to the entire Islamic/sharia stock market.

\section{CONCLUSIONS AND RECOMMENDATIONS}

\subsection{Conclusions}

Based on the empirical results reported in the previous section, the following can be concluded. First, this study finds significant evidence that univariate GARCHtype models can effectively specify the daily returns of four major Islamic indices. Second, the estimated coefficients of the GARCH $(1,1)$ model $\left(\alpha_{1}\right.$ and $\left.\beta_{1}\right)$ indicate that the conditional variance of equity returns in all four Islamic indices depends on previous own lags and past squared errors and that this phenomenon is quite persistent. Thirdly, the GARCH-M $(1,1)$ model can statistically prove the risk premium effect in daily return series in which the values of the parameter $\lambda$ are positive and significant. This means that a rise in volatility (risk) leads to an increase in mean (return). Fourth, this research also investigated the leverage effect by estimating parameters in the EGARCH $(1,1)$ TGARCH $(1,1)$, and PGARCH $(1,1)$ models.

The estimation results show strong evidence that the five univariate GARCHtype models can depict stylised features of volatility such as volatility clustering, as well as asymmetric effects in the four Islamic index series. This evidence is confirmed by the results of forecasting performance, which show that asymmetric 
GARCH-type models including EGARCH, TGARCH, and PGARCH produce smaller forecasting errors (MSE and MAE) than symmetric GARCH models. However, the very small difference values of RMSE and MAE among the univariate GARCH-type models indicate that no single one of these models is superior to the other in terms of forecasting the volatility returns of four primary Islamic indices. It can be concluded that asymmetric GARCH-type models are slightly more accurate than symmetric models when used in forecasting the volatility of four primary Islamic indices.

\subsection{Recommendations}

The volatility of Islamic financial assets is beneficial in stimulating market conditions. Amid the foregoing analyses we are able to discover that there exist various factors in Islamic stock-market indices. Therefore, according to the actual conditions found, we make the following recommendations. Investment philosophy should be broadened, because many individual and small investors lack proper understanding and skills in the measurement of financial securities. Many investors are misguided by investing only in high-risk stocks for quick returns, often leading to significant losses when buying stocks of a company with underperforming fundamental ratios. Therefore, stock-market stakeholders should promote a more rational investment philosophy, in order to enable more investors to be able to extract and analyse the useful information available in the markets. Policy makers should escalate the promotion of Islamic stocks and markets to both Muslim minority and majority countries as the key to improving the overall performance of Islamic stock indices. For future research, we suggest using other methods besides GARCH models in order to obtain different forecasting results and to update the data of the stock-market indices.

\section{REFERENCES}

Abdalla, S. Z. S., \& Winker, P. (2012). Modelling Stock Market Volatility Using Univariate GARCH Models: Evidence from Sudan and Egypt. International Journal of Economics and Finance, 4(8), 161-176. https://doi.org/10.5539/ijef. v4n8p161

Andreou, E., \& Ghysels, E. (2002). Detecting Multiple Breaks in Financial Market Volatility Dynamics. Journal of Applied Econometrics, 17(5), 579-600. https://doi. org/10.1002/jae.684

Ané, T. (2006). An Analysis of the Flexibility of Asymmetric Power GARCH Models. Computational Statistics and Data Analysis, 51(2), 1293-1311. https://doi. org/10.1016/j.csda.2005.11.002

Asteriou, D., \& Hall, S. G. F. (2011). Applied Econometrics. Palgrave Macmillan.

Ben Nasr, A., Ajmi, A. N., \& Gupta, R. (2014). Modelling the Volatility of the Dow Jones Islamic Market World Index Usinga Fractionally Integrated TimeVarying GARCH (FITVGARCH) Model. Applied Financial Economics, 24(14), 993-1004. https://doi.org/10.1080/09603107.2014.920476

Bollerslev, T. (1986). Generalised Autoregressive Conditional Heteroscedasticity. Journal of Econometrics, 31(2), 307-327. 
Chiadmi, M. S., \& Ghaiti, F. (2014). Modeling Volatility of Islamic Stock Indexes: Empirical Evidence and Comparative Analysis. International Journal of Economic Research, 11(2), 241-276.

Ding, Z., Granger, C. W. J., \& Engle, R. F. (1993). A Long Memory Property of Stock Market Returns and a New Model. Journal of Empirical Finance, 1(1), 83-106. https://doi.org/10.1016/0927-5398(93)90006-D

Engle, R. F. (1982). Autoregressive Conditional Heteroscedasticity with Estimates of the Variance of United Kingdom Inflation. Econometrica, 50(4), 987. https:// doi.org/10.2307/1912773

Engle, R. F., Lilien, D. M., \& Robins, R. P. (1987). Estimating Time Varying Risk Premia in the Term Structure: The Arch-M Model. Econometrica, 55(2), 391. https://doi.org/10.2307/1913242

Glosten, L. R., Jagannathan, R, \& Runkle, D. E. (1993). On the Relation Between the Expected Value and the Volatility of the Nominal Excess Return on Stocks. The Journal of Finance, 48(5), 1779-1801. https://doi.org/10.1111/j.1540-6261.1993. tb05128.x

Gokcan, S. (2000). Forecasting Volatility of Emerging Stock Markets: Linear Versus Non-Linear GARCH Models. Journal of Forecasting, 19(6), 499-504. https://doi. org/10.1002/1099-131X(200011)19:6<499::AID-FOR745>3.0.CO;2-P

Granger, C. W. J., Spear, S. A., \& Ding, Z. (2000). Stylized Facts on the Temporal and Distributional Properties of Absolute Returns: An Update. Statistics and Finance: An Interface, 97-120.

Hansen, P. R., \& Lunde, A. (2005). A Forecast Comparison of Volatility Models: Does Anything Beat a GARCH(1,1)? Journal of Applied Econometrics, 20(7), 873889. https://doi.org/10.1002/jae.800

Martens, M. P. E., De Pooter, M., \& van Dijk, D. J. C. (2004). Modeling and Forecasting S\&P 500 Volatility: Long Memory, Structural Breaks and Nonlinearity. SSRN Electronic Journal. https://doi.org/10.2139/ssrn.557746

Nelson, D. B. (1991). Conditional Heteroskedasticity in Asset Returns: A New Approach. Econometrica, 59(2), 347. https://doi.org/10.2307/2938260

Penzer, J., Wang, M., \& Yao, Q. (2009). Approximating Volatilitiesby Asymmetric Power GARCH Functions. Australian and New Zealand Journal of Statistics, 51(2), 201-225. https://doi.org/10.1111/j.1467-842X.2009.00542.x

Poon, S.-H., \& Granger, C. W. J. (2003). Forecasting Volatility in Financial Markets: A Review. Journal of Economic Literature, 41(2), 478-539. https://doi. org $/ 10.1257 / 002205103765762743$

Rapach, D. E., \& Strauss, J. K. (2008). Structural Breaks and GARCH Models of Exchange Rate Volatility. Journal of Applied Econometrics, 23(1), 65-90. https:// doi.org/10.1002/jae.976

Rapach, D. E., Strauss, J. K., \& Wohar, M. E. (2008). Forecasting Stock Return Volatility in the Presence of Structural Breaks. Frontiers of Economics and Globalization, 3, 381-416. https://doi.org/10.1016/S1574-8715(07)00210-2

Sclip, A., Dreassi, A., Miani, S., \& Paltrinieri, A. (2016). Dynamic Correlations and Volatility Linkages Between Stocks and Sukuk: Evidence From International Markets. Review of Financial Economics, 31, 34-44. https://doi.org/10.1016/j. rfe.2016.06.005 
Tsay, R. S. (2010). Analysis of Financial Time Series. John Wiley \& Sons, Inc. https:// doi.org/10.1002/9780470644560

Wennstrom, A. (2014). Volatility Forecasting Performance: Evaluation of GARCH Type Volatility Models on Nordic Equity Indices. Spring, 2-61.

Xie, Y. (2007). Maximum Likelihood Estimation and Forecasting for GARCH, Markov Switching, and Locally Stationary Wavelet Processes. Department of Forest Economics publications 1594, Swedish University of Agricultural Sciences, Department of Forest Economics.

Yan, B. and Jiang, H. (2008). Research of Stock Index and Futures: "Throw a Sprat to Catch a Herring"- Things to Know for Public Investors. Beijing: Social Sciences Academic Press.

Yusof, R., \& Majid, M. (2007). Stock Market Volatility Transmission in Malaysia: البورصة سوق مقارنة : الماليزية البورصة في تقلبات ال تأثير Islamic Versus Conventional Stock Market بالإسلامية التقليدية. Journal of King Abdulaziz University-Islamic Economics, 20(2), 19-40. https://doi.org/10.4197/islec.20-2.2

Zakoian, J.-M. (1994). Threshold Heteroskedastic Models. Journal of Economic Dynamics and Control, 18(5), 931-955. https://doi.org/10.1016/01651889(94)90039-6 